\title{
CORRESPONDENCE
}

Waiting lists for cardiac surgery

K K Nair, FRCS, and S R Dunn, FFARCS . . . 890

Medical care in inner cities

D C Morrell, FRCGP . . . . . . . . . . . . 890

Sexual pressures on children

G R Kinghorn, MRCP; Valerie Riches

Reverend J B Metcalfe, MB; Madeleine

Simms, MSC; M Jarmulowicz. . . . . . . . . 891

Hospital equipment "Which?"

P M Harms, MIEE . . . . . . . . . . . . 892

Comparison of the tine and Mantoux

tuberculin tests

A J Johnson, MRCP, and J A Lunn, MD . . . 892

Health Service planning and medical education

R Wilkinson, MRCP

Confidentiality of medical records

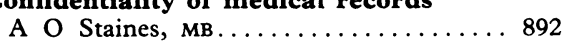

Postoperative morbidity and mortality after bleomycin treatment

I G Schraibman, FRCS; P L Goldiner, MD,

and G C Carlon, MD . . . . . . . . . . . . . . 892
Radiology work load

M D Rosewarne, FRCR; K Swinburne, DMRD

Joyce F Andrews, TDCR .......... 893

Beta-blockers in treatment of

hypertension

D M Harris, MD, and D A Richards, MD . . 894

Investigating stroke

F Mills, MRCP................. 894

Chlormethiazole addiction

M M Glatt, FRCPSYCH . . . . . . . . . . . 894

Breathing other people's smoke

R S F Schilling, FRCP, and A Bouhuys;

B J-L Sudan, MD; Betty Brody. . . . . . . . . 895

Uniform style for biomedical journals

R Carlisle, FRCP, and others . . . . . . . 895

Misdiagnosis of amoebiasis

A L Jeanes, FRCPATH............ 895

Melatonin as a marker for pineal tumours

S G Barber, MRCP. . . . . . . . . . . 896

Whooping cough

D Jenkinson, мв ............. 896
Arenaviruses in perspective

K M Pavri . . . . . . . . . . . . . . . . . . . . 896

Underdiagnosis of childhood asthma

A D Clift, MD, and B Jean Day ......... 896

HDL cholesterol and coronary artery occlusion

J J Barboriak, sCD . . . . . . . . . . . . . 897

Adverse reactions to intravenous

induction agents

H L Thornton, FFARCS...

Lord Mayor Treloar Hospital, Alton

M C Wilkinson, FRCs.............. 897

Negotiating rights for junior hospital doctors

T McFarlane, MRCog. . . . . . . . . . . . . . 897

Distribution of registrars

V M Demmery. . . . . . . . . . . . . . 898

General practice records

J T Hart, FRCGP; H W K Acheson, FRCGP . . 898

Related ancillary staff

H Gordon, мғсм............... 898

Priorities in planning

R H Hardy, DM.
Correspondents are urged to write briefly so that readers may be offered as wide a selection of letters as possible. So many are being received that the omission of some is inevitable. Letters must be signed personally by all their authors. As stated each week in "Instructions to authors" no letter will be acknowledged unless a stamped addressed envelope or an international reply coupon is enclosed.

\section{Waiting lists for cardiac surgery}

SIR,-Recently it has been revealed that there is a variation in the length of waiting lists for cardiac operations in England. This culminated in two patients going to private clinics in London for their operations.

At the cardiothoracic unit in Castle Hill Hospital, Cottingham, North Humberside, there is no waiting list for cardiac operations. The maintenance of expertise, facilities, and medical, nursing, and technical personnel is

\section{Medical care in inner cities}

SIR,-I have read with interest the opinions expressed in the discussion on medical care in inner cities (19 August, p 545) and the ensuing correspondence. Dr R Law (9 September, $p$ 767) condemns the medical schools of London for their lack of interest in this problem. My contribution to this correspondence is based on facts collected by the district administrator and myself in visits to the surgeries of $50 \%$ of the general practitioners in the St Thomas's District. From this survey and a study of the problems of other boroughs, it is possible to draw certain conclusions.

(1) The inner city problem in London varies from one borough to another. In Lambeth, for instance, patients have no problem in finding a general practitioner. This is in contrast to the serious problems experienced in Kensington, Chelsea, and Westminster, where list sizes tend to be low but many doctors are expensive. Is it time for us to have a national waiting list for this type of surgery? Within the NHS we could avoid some of the waitinglist mortality which occurs in some parts of the country.

K K NAIR S R DUNN

Department of Anaes hesia,

Hull Royal Infirmary,

engaged in private practice. Dr D Stephens (p 767) draws attention to this problem and suggests that if practice in Southwark was more profitable than in Harley Street the standard of care would be the best in the world. I know of no evidence that the standards of general practitioner care in Harley Street are superior to those in Southwark and would be intrigued to apply the criteria suggested by Dr John Fry (p 767) in both situations.

(2) The provision of suitable premises presents a serious problem in London and many are too small to make possible the development of the primary health care team. Most of the doctors we visited were not interested in health centres, some because they were afraid of increased expenses, some because they did not see the relevance to the primary health care team, and some because the recent behaviour of our political leaders in the Health Service made them anxious about their professional freedom. The best premises we visited were purpose-built by local authorities and rented by the doctors, but many doctors described difficulties in obtaining planning permission and space to develop their own premises.

(3) The question of recruitment to general practice in London is crucial. New vocationally trained doctors are unlikely to practise in London unless they are taken into an existing partnership. Death and retirement vacancies tend to go to doctors who have qualified abroad and spent several years as assistants in general practice in Britain. The experience in general practice which they have acquired in this way gives them a great advantage with selection committees.

(4) The greatest problem which we encountered in our visits was that of isolation. Nearly one-third of the doctors were singlehanded and had little contact with their colleagues in general practice, the specialists to whom they referred patients, their community nurses, or health visitors. Despite this, most of them were content with the services they provided, the premises in which they worked, and the facilities provided by the hospital. The fact that general practice in the last two decades has changed from a demandorientated service to one concerned with continuity of care and prevention was not always appreciated. This is not a problem which can be solved by legislation; it requires education.

It would be a great pity if the concept of primary, personal, and continuing care by independent contractors was rejected in the inner cities simply because the problems are difficult to solve. It is only in one or two boroughs that the mobility of the population precludes continuity of care. In most areas the mobility is confined to about $20 \%$ of the population while 60 to $80 \%$ remain stable. What is required is a careful analysis of the problems at district level, and in London this 
means that each teaching hospital must accept responsibility for its own district.

If we wish to attract high-quality graduates to general practice in the London teaching districts we must offer them incentives. These include opportunities to take part in undergraduate and postgraduate teaching, facilities for undertaking research, good communications with specialists through, for instance, postgraduate medical centres, and close support from nurses and health visitors. I would like to think that at least one of the London teaching hospitals has shown that this approach is possible and would be interested to know if any other district administrator in the country has personally visited over half the general practitioners in his district.

DAVID MORRELL

Department of Community Medicine,

St Thomas's

\section{Sexual pressures on children}

SIR,-The Responsible Society (29 July, $p$ 353) rightly attacks the increasing sexual pressures on children which are promoted by teenage magazines and the irresponsible use of sex by the advertising agencies and the media. Their assertion that the availability of contraceptive services for under-age girls is a further major pressure resulting in the rising number of unwanted pregnancies and venereal disease in these girls is highly questionable, however.

The figures relating to the number of girls aged less than 16 attending the venereal disease clinic in a major industrial city are relevant in this context (see table). Although there has been a large rise in the number of gonococca infections in this population since 1967, only five $(6.0 \%)$ of the total 84 girls attending the department and two $(7 \cdot 7 \%)$ of 26 with gonorrhoea used any contraceptive measures.

Gonorrhoea in girls under 16 years in Sheffield

\begin{tabular}{|c|c|c|c|}
\hline & 1967 & 1972 & 1976 \\
\hline $\begin{array}{l}\text { Total gonorrhoea } \\
\text { infections }\end{array}$ & 2 & 10 & 35 \\
\hline $\begin{array}{l}\text { No of individuals } \\
\text { No of individuals with } \\
\text { more than one gono- } \\
\text { coccal infection in same } \\
\text { year }\end{array}$ & 2 & 10 & $\begin{array}{c}26 \\
6 \\
(23 \cdot 1 \%)\end{array}$ \\
\hline $\begin{array}{l}\text { No of individuals with } \\
\text { complicated gonor- } \\
\text { rhoea (salpingitis, } \\
\text { septicaemia). }\end{array}$ & & & $(11.5 \%)$ \\
\hline $\begin{array}{l}\text { No using any form of } \\
\text { contraception. }\end{array}$ & & & $\begin{array}{c}2 \\
(7 \cdot 7 \%\end{array}$ \\
\hline $\begin{array}{ccc}\text { No in care of local } \\
\text { authority } & \ldots & \ldots\end{array}$ & & $\begin{array}{c}8 \\
(80 \%)\end{array}$ & $\left.\begin{array}{c}14 \\
\left(53 \cdot 8^{\circ}\right.\end{array}\right)$ \\
\hline $\begin{array}{l}\text { Total gonorrhoea infec- } \\
\text { tions in women }\end{array}$ & 204 & 341 & 517 \\
\hline
\end{tabular}

In both 1972 and 1976 the majority of underage girls presenting with gonorrhoea had been at the time of attendance, or were subsequently, taken into the care of the local authority. This testifies to the lack or failure of parental guidance. The increasing national figures for unwanted pregnancies also suggest that the increasing availability of contraceptive services is at most coincidental rather than causative.

Our experience is that the majority of these girls who acquire venereal disease are emotionally immature and poorly motivated to seek contraceptive advice, and their profound ignorance about venereal disease leads them to take increased risks, fail to recognise symptoms, and present late for diagnosis. Both the complication rate and repeater rate in the under-age girls attending this clinic are twice that for all women aged over 16 . Because many have already run away from home and use their sexuality to promote new relationships they are easily exploited. Many drift into prostitution.

Whatever sex education these girls have received has manifestly failed to protect them from the increasing sexual pressures imposed upon them. The Responsible Society's wellmeaning intentions would be better served if their attacks were directed against the other agencies which increase these pressures and by ensuring that responsible sex education is given to all children. This should surely be provided by those who are properly trained, informed, and able to impart this information to young people. This education must now include an increased emphasis on the advers effects of sexual activity in terms of psychological trauma and the rapidly rising rates for unwanted pregnancies and venereal disease, not simply instruction into the mechanics of sex.

Special Clinic,

G R KINGHORN

Royal Infirmary

Sheffield

SIR,-I hope you will be good enough to allow me space to reply to damaging assertions in Dr Anne Savage's letter (9 September p 770).

I do not propose to deal with Dr Savage's unworthy suggestions about the professional integrity of medical members of the Respon sible Society, as their concern for the welfare of the young was clearly expressed in their letter (29 July, p 353). I simply seek the opportunity to correct Dr Savage's assertion that her supply of the society's literature stopped following a telephone conversation with me. It is perfectly true that after discussion with a television producer Dr Savage told me that she did not want to take part in a confrontation situation. This was reasonable and I felt sympathy, for I have never felt happy about the way in which television, for purposes of entertainment, seeks to polarise differences instead of encouraging constructive debate. As for the subject of the proposed television programme, I explained that the society's actual concern was that, in our opinion, particular organisations promote promiscuity in the young.

Dr Savage's supply of literature ceased because she did not renew her subscription following two reminders from the society's membership secretary, a normal administrative procedure. In times of high printing costs Dr Savage cannot expect to receive literature free of charge.

VALERIE RICHES National Honorary

Milton Keynes, Bucks The Responsible Society

SIR,-It seems that we are all agreed that teenage sexual intercourse leads to more unhappiness than fulfilment, so may we move on to the next stage in the discussion? We don't all recognise that an authoritarian approach to teenagers and to teenage-magazine editors will not change their habits.

Most of your correspondents on this subject write with high emotions; in my opinion we need to work out coolly a reasoned case to support our point of view because that is the only kind of communication we can hope to be respected by our children. We need to measure the problem and compare it with other social evils so that all can see the size of health hazard it is. Has anyone done this?

Until we have changed teenage behaviour we have, in my view, a moral obligation to continue to protect them in any way we can, including providing contraceptive advice, and to comfort and treat the casualties.

J B Metcalfe

Madeley,

Telford, Salop

SIR,-Dr John S Bradshaw (2 September, p 701) seems to object strongly to my views (12 August, p 499), while at the same time misrepresenting them. Perhaps I could clear up a few confusions:

(1) He states that those who support contraceptive services for the young believe there is nothing to sex "finer than mere copulation." This must be a figment of Dr Bradshaw's overheated imagination, since there is nothing in my letter nor in that of any of the other correspondents that could lead any reasonable person to suppose anything so absurd.

(2) By "political" I mean, among other things, the concerted effort in the House of Commons on 13 July by a group of extreme right-wing supporters of the Responsible Society and its associated pressure groups, including Mrs Jill Knight, Mr John Stokes, and $\mathrm{Mr}$ Patrick Cormack, to embarrass the Secretary of State for, in the words of $\mathrm{Mr}$ Andrew Bowden, "funding contraception for children under the age of consent."1

(3) Dr Bradshaw then states that to offer advice on a subject is the same as "promoting" it. Irish girls are not so fortunate as to have access to advice about birth control, still less to have it "promoted." Yet, as he must know, every year the number of girls from the Irish Republic coming to England for abortion increases steadily. In 19761800 came; in 1977,2200 came; this year the figure will be more than 2400. Deliberately keeping the young in total ignorance does not seem to be too successful in stemming immorality.

London NW11

Madeleine Simms

${ }^{1}$ Hansard, House of Commons, Written Answers to Questions, 11 July 1978, col 457 .

SIR,-I have been following with great interest the recent correspondence on this subject. It is not surprising that many of the arguments proposed have been on ethical grounds, since man has always spent hours pondering over the higher motives of his activity, yet we always seem to ignore the essential fact that we are also animals and as such are influenced by basic biological laws. It is by ignoring the fundamental biological nature of Homo sapiens that we will put future generations in peril.

Humans, unlike any other animals, are sexually receptive at virtually any time. Why? In order to understand human sexuality properly we must look at our origins and examine why evolution has provided us with such intense sexual desires. If we look around the animal kingdom we find that where the burden of rearing the offspring is too great for one parent, then there is the development of a powerful pair-bond between the parents (an 